\title{
Solid-Supported Synthesis of Hyperbranched Polymer with Discrete Conjugated Units
}

\author{
Patricia Guadarrama, Lioudmila Fomina, Vladimir Pankov, \\ Wilber Matus, ${ }^{*}$ and Serguei FominE ${ }^{\dagger}$ \\ Instituto de Investigaciones en Materiales, Universidad Nacional Autónoma de México, \\ Apartado Postal 70-360, CU, Coyoacán, México DF 04510, México \\ * Instituto de Quimica, Universidad Nacional Autónoma de México, Apartado Postal $70-360$, \\ CU, Coyoacán, México DF 04510, México
}

(Received August 31, 1998)

\begin{abstract}
Novel hyperbranched polymer poly(4-(5-hexynyloxy)- $\beta, \beta$-dibromostyrene) was synthesized by Pd-catalyzed cross-coupling reaction of 4-(5-hexynyloxy)- $\beta, \beta$-dibromostyrene in solution and using an aromatic polyamide solid support. According to the NMR data the degree of branching of the polymer obtained in solution without solid support was of $30-35 \%$, while when using solid support the degree of branching increased to $60-65 \%$. However, molecular weight of detached Poly-6 was lower that of the polymer obtained in solution. It seems that monomer molecules trapped in the vicinity of growing polymer chain by the polymeric support have more time to react with second bromine atoms of dibromovinyl groups, thus increasing branching of the polymer. Drop in molecular weight when using solid support is attributed to steric hindrance due to polymeric support, thus limiting the molecular weight of the attached polymer.
\end{abstract}

KEY WORDS Hyperbranched Polymers / Solid-Supported Polymerization /

Hyperbranched polymers obtained from $\mathrm{AB}_{2}$ type monomers are taking on interest. There is growing interest in macromolecules with architectures differing from classical linear polymers as these new architectures may exhibit unusual behavior and possess properties that differ from those of linear polymers. Some advantages of hyperbranched polymers are high solubility compared to linear analogs and high concentrations of end groups even for high polymers.

The present authors are interested in the development of polymers with new chemical structures for photo-, electroluminescence and nonlinear optics and previously reported the synthesis and polymerization of a new $\mathrm{AB}_{2}$ monomer $\beta, \beta^{\prime}$-dibromo-4-ethynyl styrene by the $\mathrm{Pd}$ catalyzed cross-coupling to produce fully aromatic conjugated polymer containing $\beta, \beta$-diethynylstyryl conjugated groups. ${ }^{1}$ To increase the tractability of hyperbranched polymer, flexible aliphatic spacers were incorporated into polymer chain, resulting in hyperbranched polymer containing $\beta, \beta$-diethynylstyryl discrete conjugated units. ${ }^{2}$ The polymers were readily soluble in chloroform, showing strong photo- and electroluminescence.

An undesirable feature of one-step $\mathrm{AB}_{2}$ polymerization is loss of control in molecular weight accompanied by a broad molecular weight distribution. ${ }^{3}$ Hyperbranched polymerization on an insoluble solid support provides polymers with polydispersity $<1.3$ and good molecular weight control in the range $5-25 \mathrm{kDa}$.

This work developed solid-supported synthesis of polymers with discrete conjugated units and compares the properties of polymer prepared in solution with those of polymer synthesized using solid support.

\footnotetext{
$\dagger$ To whom correspondence should be addressed.
}

\section{EXPERIMENTAL}

\section{Materials}

Terephthaloyl chloride was crystallized from hexane. All other reagents were used as received from Aldrich.

\section{Solid Support and Monomer Synthesis}

4,4'-Diamino-4"-hydroxy Triphenylmethane (2). A mixture of 4-hydroxybenzaldehyde (1) (10 g, $82 \mathrm{mmol})$, phenylammonium hydrochloride $(1 \mathrm{~g})$ and aniline $(30 \mathrm{~g}$, $340 \mathrm{mmol}$ ) was stirred at $120^{\circ} \mathrm{C}$ under nitrogen flow for $3.5 \mathrm{~h}$. The reaction mixture was extracted with hot chlorobenzene, The solid precipitated was filtered off and crystallized from $o$-dichlorobenzene. Yield $46 \%, \mathrm{mp}=100$ $103^{\circ} \mathrm{C}$. ${ }^{1} \mathrm{H}$ NMR (dimethyl sulfoxide (DMSO)- $d_{6}$ ) 9.14 (s, $1 \mathrm{H}, \mathrm{OH}), 6.85(\mathrm{~d}, 2 \mathrm{H}, J=8.4 \mathrm{~Hz}$, meta to $\mathrm{OH}), 6.68$ (d, $4 \mathrm{H}, J=8.4 \mathrm{~Hz}$, meta to $\left.\mathrm{NH}_{2}\right), 6.63(\mathrm{~d}, 2 \mathrm{H}, J=8.4 \mathrm{~Hz}$ ortho to $\mathrm{OH}), 6.46\left(\mathrm{~d}, 4 \mathrm{H}, J=8.4 \mathrm{~Hz}\right.$, ortho to $\left.\mathrm{NH}_{2}\right)$, 5.01 (s, 1H, CH aliph.), 4.83 (s, 4H, $\mathrm{NH}_{2}$ ). ${ }^{13} \mathrm{C} \mathrm{NMR}$, $155.5\left(\mathrm{C}_{\mathrm{ar}}-\mathrm{O}\right), 146.2\left(\mathrm{C}_{\mathrm{ar}}-\mathrm{N}\right), 136.2\left(\mathrm{C}_{\mathrm{ar}}\right.$ para to $\left.\mathrm{OH}\right)$, $130.2\left(\mathrm{C}_{\mathrm{ar}}\right.$ meta to $\left.\mathrm{OH}\right), 129.8\left(\mathrm{C}_{\mathrm{ar}}\right.$ meta to $\left.\mathrm{NH}_{2}\right), 126.3$ $\left(\mathrm{C}_{\mathrm{ar}}\right.$ para to $\left.\mathrm{NH}_{2}\right), 114.5\left(\mathrm{C}_{\mathrm{ar}}\right.$ ortho to $\left.\mathrm{OH}\right) 113.8\left(\mathrm{C}_{\mathrm{ar}}\right.$ ortho to $\mathrm{NH}_{2}$ ), 54.1 (C aliph).

Poly (4,4'-diphenylene-4"-hydroxyphenyl methane) Terephthalamide $(\mathrm{SOH})$. To a solution containing $3.800 \mathrm{~g}$ (13.10 mmol) diamine 2 and $50 \mathrm{ml} \mathrm{N}$-methylpyrrolidone (NMP) terephthaloyl chloride $(2.709 \mathrm{~g}, 13.34 \mathrm{mmol})$ was added slowly at $0^{\circ} \mathrm{C}$. The viscous solution was poured into water. The polymer was filtered off, rinsed with water and dried in vacuum. Yield $=98 \% .{ }^{1} \mathrm{H}$ NMR (DMSO$\left.d_{6}\right), 10.4(\mathrm{~s}, 2 \mathrm{H}, \mathrm{NH}), 9.34(\mathrm{~s}, 1 \mathrm{H}, \mathrm{OH}), 8.09$ (s, 4H arom, terephthaloyl), $7.73(\mathrm{~d}, 4 \mathrm{H}, J=8.4 \mathrm{~Hz}$, ortho to $\mathrm{NH}), 7.11$ (d, $4 \mathrm{H}, J=8.4 \mathrm{~Hz}$, meta to $\mathrm{NH}), 6.35$ (d, $2 \mathrm{H}, J=8.4 \mathrm{~Hz}$, meta to $\mathrm{OH}), 6.72(\mathrm{~d}, 2 \mathrm{H}, J=8.4 \mathrm{~Hz}$, ortho to $\mathrm{OH}), 5.46$ (s, 1H, CH aliph), ${ }^{13} \mathrm{C} \mathrm{NMR,} 164.7(\mathrm{C}=\mathrm{O}), 155.6\left(\mathrm{C}_{\mathrm{ar}}-\mathrm{O}\right)$, $140.1\left(\mathrm{C}_{\mathrm{ar}}-\mathrm{NH}\right), 137.4,137.0\left(C_{a r}-\mathrm{CO}, \mathrm{C}_{\mathrm{ar}}\right.$ para to $\left.\mathrm{NH}\right)$, $134.2\left(\mathrm{C}_{\mathrm{ar}}\right.$ para to $\left.\mathrm{OH}\right), 129.9\left(\mathrm{C}_{\mathrm{ar}}\right.$ terephthaloyl $), 129.1$ $\left(\mathrm{C}_{\mathrm{ar}}\right.$ meta to $\left.\mathrm{NH}\right), 127.7\left(\mathrm{C}_{\mathrm{ar}}\right.$ ortho to $\left.\mathrm{NH}\right), 120.5\left(\mathrm{C}_{\mathrm{ar}}\right.$ 
meta to $\mathrm{OH}), 115.1\left(\mathrm{C}_{\mathrm{ar}}\right.$ ortho to $\left.\mathrm{OH}\right), 54.15(\mathrm{CH}$ aliph $)$.

Poly-(4,4'-diphenylene-4"-(4-bromobenzoyloxy)phenyl methane) Terephthalamide (S-OOCPhBr). Polymer $\mathrm{SOH}(5.27 \mathrm{~g})$ was treated with equimolar amount of 4 bromobenzoyl chloride in a mixture of methylene chloride $(40 \mathrm{ml})$ and pyridine $(30 \mathrm{ml})$ for $24 \mathrm{~h}$. The solid was filtered off, washed with diluted $\mathrm{HCl}$ and dried in vacuum to give $6.72 \mathrm{~g}$ of product $(89 \%$ yield). The polymer was not soluble any longer in common organic solvents. IR $\left(\mathrm{cm}^{-1}\right) 3321(\mathrm{~N}-\mathrm{H}), 1736(\mathrm{C}=\mathrm{O}$ ester $), 1664(\mathrm{C}=\mathrm{O}$ amide), Elemental analysis $\left(\mathrm{C}_{34} \mathrm{H}_{23} \mathrm{~N}_{2} \mathrm{O}_{4} \mathrm{Br}\right)_{n}$ Calc (\%) Br 13.3 Found (\%) Br 11.1.

5-Hexynyl Toluene Sulfonate (4). A mixture of 5hexyne-1-ol $(3.9 \mathrm{~g}, 39.7 \mathrm{mmol})$, TsCl $(9.1 \mathrm{~g}, 47.3 \mathrm{mmol})$, methylene chloride $(40 \mathrm{ml})$ and pyridine $(10 \mathrm{ml})$ was stirred $24 \mathrm{~h}$ at room temperature, The reaction mixture was poured into dilute $\mathrm{HCl}$. The product was taken into chloroform and dried with $\mathrm{MgSO}_{4}$. Excess solvent was removed in vacuum. The product was yellowish oil. Yield $=81 \% .{ }^{1} \mathrm{H} \mathrm{NMR}\left(\mathrm{CDCl}_{3}\right) ; 7.76(\mathrm{~d}, 2 \mathrm{H}, J=8.1 \mathrm{~Hz}$, meta to $\left.\mathrm{CH}_{3}\right), 7.32\left(\mathrm{~d}, 2 \mathrm{H}, J=8.1 \mathrm{~Hz}\right.$, ortho to $\mathrm{CH}_{3}$ ), $4.05\left(\mathrm{t}, 2 \mathrm{H}, J=6.3 \mathrm{~Hz}, \mathrm{OCH}_{2}\right), 2.41\left(\mathrm{~s}, 3 \mathrm{H}, \mathrm{CH}_{3}\right), 2.12$ $\left(\mathrm{m}, 2 \mathrm{H}, \equiv \mathrm{C}-\mathrm{CH}_{2}-\right), 2.00(\mathrm{~m}, 1 \mathrm{H}, \mathrm{HC} \equiv), 1.74-1.65$ $\left(\mathrm{m}, 2 \mathrm{H}, \mathrm{CH}_{2} \mathrm{O}-\mathrm{CH}_{2}-\mathrm{CH}_{2}\right), 1.55-1.49(\mathrm{~m}, 2 \mathrm{H}$, $\equiv \mathrm{C}-$ $\left.\mathrm{CH}_{2}-\right) .{ }^{13} \mathrm{C} \mathrm{NMR} ; 144.9\left(\mathrm{C}_{\mathrm{ar}}-\mathrm{SO}_{2}\right), 133.1\left(\mathrm{C}_{\mathrm{ar}}-\mathrm{CH}_{3}\right)$, 129.6, $127.9\left(\mathrm{C}_{\mathrm{ar}}\right), 83.7(-\mathrm{C} \equiv \mathrm{CH}), 70.1\left(\mathrm{OCH}_{2}\right), 69.3$ $(-\mathrm{C} \equiv \mathrm{CH}), 27.8\left(-\mathrm{OCH}_{2} \mathrm{CH}_{2} \mathrm{CH}_{2}-\right), 24.3\left(-\mathrm{OCH}_{2} \mathrm{CH}_{2}-\right.$ $\left.\mathrm{CH}_{2}-\right), 21.7\left(\mathrm{CH}_{3}\right), 17.7\left(-\mathrm{CH}_{2}-\mathrm{C} \equiv \mathrm{CH}\right)$.

4-(5-Hexynyloxy)benzaldehyde (5). A mixture of tosylate 4 (12.85 g, $50.98 \mathrm{mmol})$, 4-hydroxybenzaldehyde $(6.22 \mathrm{~g}, 50.98 \mathrm{mmol}), \mathrm{K}_{2} \mathrm{CO}_{3}(14.2 \mathrm{~g}, 102 \mathrm{mmol})$ and NMP $(40 \mathrm{ml})$ was stirred for $24 \mathrm{~h}$ at $70^{\circ} \mathrm{C}$. The reaction mixture was poured into dilute $\mathrm{HCl}$ and the product was taken into chloroform and washed with $2 \% \mathrm{NaOH}$ solution. Excess solvent was evaporated and the residue was crystallized from hexane and then from methanol. Yield $=70 \%, \mathrm{mp}=38-39^{\circ} \mathrm{C} .{ }^{1} \mathrm{H} \mathrm{NMR}\left(\mathrm{CDCl}_{3}\right) ; 9.90(\mathrm{~s}$, $1 \mathrm{H}, \mathrm{CH}=\mathrm{O}), 7.82(\mathrm{~d}, 2 \mathrm{H}, J=8.7 \mathrm{~Hz}$ ortho to $\mathrm{CHO}), 6.98$ (d, $2 \mathrm{H}, J=8.7 \mathrm{~Hz}$, meta to $\mathrm{CHO}), 4.74(\mathrm{t}, 2 \mathrm{H}, J=6.3 \mathrm{~Hz}$, $\left.\mathrm{OCH}_{2}\right), 2.29\left(\mathrm{dd}, 2 \mathrm{H}, J_{1}=6.6 \mathrm{~Hz}, J_{2}=2.7 \mathrm{~Hz},-\mathrm{CH}_{2}-\mathrm{C} \equiv\right)$, $1.99-1.90\left(\mathrm{~m}, 3 \mathrm{H}, \mathrm{HC} \equiv \mathrm{C}-,-\mathrm{OCH}_{2} \mathrm{CH}_{2}-\right), 1.80-1.70$ (m, 2H, $\left.-\mathrm{CH}_{2} \mathrm{CH}_{2}-\mathrm{C} \equiv\right) .{ }^{13} \mathrm{C} \mathrm{NMR} ; 190.8(\mathrm{CH}=\mathrm{O})$, $164.0\left(\mathrm{C}_{\mathrm{ar}}-\mathrm{O}\right), 132.0\left(\mathrm{C}_{\mathrm{ar}}\right.$ ortho to $\left.\mathrm{CHO}\right), 129.9\left(\mathrm{C}_{a r}{ }^{-}\right.$ $\mathrm{CH}=\mathrm{O}), 114.7\left(\mathrm{C}_{\mathrm{ar}}\right.$ meta to $\left.\mathrm{CHO}\right), 83.6(-\mathrm{C} \equiv \mathrm{CH}), 68.8$ $(-\mathrm{C} \equiv \mathrm{CH}), 67.7\left(\mathrm{OCH}_{2}\right), 28.1\left(-\mathrm{OCH}_{2} \mathrm{CH}_{2} \mathrm{CH}_{2}-\right), 24.9$ $\left(-\mathrm{OCH}_{2} \mathrm{CH}_{2} \mathrm{CH}_{2}-\right), 18.1\left(-\mathrm{CH}_{2}-\mathrm{C} \equiv \mathrm{CH}\right)$.

Poly-(4,4'-diphenylene-4"-(4-(6-(4-formylphenyloxy)hexyn-1-yl))benzoyloxy)phenyl Methane (7). $1.3 \mathrm{~g} \mathrm{S-}$ $\mathrm{OOCPhBr}$ was dispersed in a mixture of triethylamine/ dioxane $=1 / 1.3$ under nitrogen. Triphenylphosphine (TPP) (0.163 g), CuI (0.064 g), Pd(TPP $)_{2} \mathrm{Cl}_{2}(0.091 \mathrm{~g})$ and compound $5(0.44 \mathrm{~g}, 2.16 \mathrm{mmol})$ were added to the reaction and the mixture was refluxed overnight. The solid precipitate was filtered off, washed with methanol and water and dried in vacuum. Yield $=87 \%$ (according to the weight uptake) IR $\left(\mathrm{cm}^{-1}\right) 3400(\mathrm{~N}-\mathrm{H}), 2850(\mathrm{C}-\mathrm{H}$ aldehyde), $2230\left(-\mathrm{C}_{\mathrm{ar}}-\mathrm{C} \equiv \mathrm{C}-\mathrm{CH}_{2}\right), 1736(\mathrm{C}=\mathrm{O}$ ester $)$, $1680(\mathrm{C}=\mathrm{O}$ aldehyde) $1655(\mathrm{C}=\mathrm{O}$ amide $)$.

Poly-(4,4'-diphenylene-4" -(4-(6-( $\beta, \beta$-dibromo-4-styryloxy)hexyn-1-yl))benzoyloxy)phenyl Methane: (SOOCPh$\left.\equiv-\left(\mathrm{CH}_{2}\right)_{4}-\mathrm{OPhCH}=\mathrm{CBr}_{2}\right)$. To a solution containing dibromotriphenylphosphorane prepared from $\mathrm{CBr}_{4}$ $(5.59 \mathrm{~g}, 7.81 \mathrm{mmol})$, and TPP $(4.10 \mathrm{~g}, 15.6 \mathrm{mmol})$ in $70 \mathrm{ml}$
$\mathrm{CH}_{2} \mathrm{Cl}_{2}$ polymer $7(1.14 \mathrm{~g})$ was added under nitrogen. The reaction mixture was stirred overnight at room temperature. The solid was filtered off, washed with methylene chloride and dried in vacuum. Yield $=100 \%$ (according to the weight uptake). IR $\left(\mathrm{cm}^{-1}\right) 3400$ $(\mathrm{N}-\mathrm{H}),(\mathrm{C}-\mathrm{H}$ aldehyde $), 2230\left(-\mathrm{C}_{\mathrm{ar}}-\mathrm{C} \equiv \mathrm{C}-\mathrm{CH}_{2}\right), 1736$ $(\mathrm{C}=\mathrm{O}$ ester $), 1655(\mathrm{C}=\mathrm{O}$ amide $)$ Elemental analysis: $\left(\mathrm{C}_{48} \mathrm{H}_{36} \mathrm{~N}_{2} \mathrm{O}_{5} \mathrm{Br}_{2}\right)_{n}$ Calc (\%) Br 18.18 Found (\%) Br 16.0 .

4-(5-Hexynyloxy)- $\beta, \beta$-dibromostyrene (6). To a solution containing dibromotriphenylphosphorane prepared from $\mathrm{CBr}_{4}(11.71 \mathrm{~g}, 35.3 \mathrm{mmol})$ and TPP (18.5 g, 70.6 $\mathrm{mmol})$ in $30 \mathrm{ml} \mathrm{CH} \mathrm{Cl}_{2}$ compound $6(7.13 \mathrm{~g}, 35.3 \mathrm{mmol})$ dissolved in $40 \mathrm{ml} \mathrm{CH}_{2} \mathrm{Cl}_{2}$ was added slowly at room temperature under nitrogen and stirred for $3 \mathrm{~h}$. Excess solvent was removed under reduced pressure and the residue was extracted twice with hot hexane. The solid precipitated from hexane solution was filtered off and purified column chromatography on $\mathrm{SiO}_{2}$ (hexane), Yield $=58 \%, \mathrm{mp}=27-28^{\circ} \mathrm{C} .{ }^{1} \mathrm{H} \mathrm{NMR}\left(\mathrm{CDCl}_{3}\right) 7.51(\mathrm{~d}$, $2 \mathrm{H}, J=9.3 \mathrm{~Hz}$, ortho to $\left.\mathrm{CH}=\mathrm{CBr}_{2}\right), 7.39(\mathrm{~s}, 1 \mathrm{H}$, $\left.\mathrm{CH}=\mathrm{Br}_{2}\right), 6.85\left(\mathrm{~d}, 2 \mathrm{H}, J=9.3 \mathrm{~Hz}\right.$, meta to $\left.\mathrm{CH}=\mathrm{CBr}_{2}\right)$, $4.00\left(\mathrm{t}, 2 \mathrm{H}, J=5.7 \mathrm{~Hz}, \mathrm{OCH}_{2}\right), 2.30\left(\mathrm{dd}, 2 \mathrm{H}, J_{1}=6.6 \mathrm{~Hz}\right.$, $\left.J_{2}=3.0 \mathrm{~Hz}, \equiv \mathrm{C}-\mathrm{CH}_{2}\right), 1.80(\mathrm{t}, 1 \mathrm{H}, J=3.0 \mathrm{~Hz}, \mathrm{H} \equiv \mathrm{C}-)$, $1.78-1.70\left(\mathrm{~m}, 2 \mathrm{H}, \mathrm{OCH}_{2}-\mathrm{CH}_{2}\right), 1.60-1.50(\mathrm{~m}, 2 \mathrm{H}$, $\left.\equiv \mathrm{C}-\mathrm{CH}_{2} \mathrm{CH}_{2}\right), \quad{ }^{13} \mathrm{C} \quad \mathrm{NMR} ; \quad 159.1 \quad\left(\mathrm{C}_{\mathrm{ar}} \mathrm{O}\right), \quad 136.3$ $\left(\mathrm{CH}=\mathrm{CBr}_{2}\right), 129.9\left(\mathrm{C}_{\mathrm{ar}}\right.$ ortho to $\left.\mathrm{CH}=\mathrm{CBr}_{2}\right), 127.7$ $\left(C_{a r}-\mathrm{CH}=\mathrm{CBr}_{2}\right), 114.3\left(\mathrm{C}_{\mathrm{ar}}\right.$ meta to $\left.\mathrm{CH}=\mathrm{CBr}_{2}\right), 87.2$ $\left(\mathrm{CH}=C \mathrm{Br}_{2}\right), 84.0 \quad(\mathrm{HC} \equiv \mathrm{C}-), 68.7 \quad(\mathrm{HC} \equiv \mathrm{C}-), 67.3$ $\left(\mathrm{OCH}_{2}\right), 28.2\left(\mathrm{OCH}_{2} \mathrm{CH}_{2}\right), 25.0\left(\mathrm{CH}_{2} \mathrm{CH}_{2} \mathrm{C} \equiv\right), 18.1$ $\left(\mathrm{CH}_{2} \mathrm{CH}_{2} \mathrm{C} \equiv\right)$.

\section{Polymerization}

Polymerization of Monomer 6 without Support. To monomer $6(1.48 \mathrm{~g} \mathrm{mmol})$ dissolved in $30 \mathrm{ml}$ dioxane/ triethylamine mixture $=1 / 1, \mathrm{TPP}(0.24 \mathrm{~g}), \mathrm{CuI}(0.05 \mathrm{~g})$, and $\mathrm{Pd}(\mathrm{TPP})_{2} \mathrm{Cl}_{2}(0.04 \mathrm{~g})$ were added under nitrogen. The reaction mixture was stirred for $15 \mathrm{~h}$ under reflux. The reaction mixture was poured into methanol, the fibrous precipitate was filtered off, washed with methanol, purified by reprecipitation from chloroform to methanol and dried in vacuum Yield $=88 \%$.

Polymerization of Monomer 6 in the Presence of Solid Support. $\mathrm{S}-\mathrm{OOCPhBr}$ : To a reaction mixture containing $\mathrm{S}-\mathrm{OOCPhBr}(0.674 \mathrm{~g}, 1.12 \mathrm{mmol})$, TPP $(0.022 \mathrm{~g}), \mathrm{CuI}$ $(0.0065 \mathrm{~g}), \mathrm{Pd}(\mathrm{TPP})_{2} \mathrm{Cl}_{2}(0.0087 \mathrm{~g})$ triethylamine $(15 \mathrm{ml})$ and dioxane $(10 \mathrm{ml})$ monomer $6(2.0 \mathrm{~g}, 5.59 \mathrm{mmol})$, dissolved in dioxane $(30 \mathrm{ml})$ was added during $2 \mathrm{~h}$ at $80^{\circ} \mathrm{C}$ under nitrogen. The reaction was stirred under reflux overnight. The solid was filtered off, washed with methanol and dried in vacuum. To cleave the polymer bound material, the product was stirred with $1.5 \mathrm{~g} \mathrm{~K}_{2} \mathrm{CO}_{3}$ in $150 \mathrm{ml}$ methanol for $24 \mathrm{~h}$. The solid was filtered off and extracted with chloroform.

$\left(\mathrm{SOOCPh}-\equiv-\left(\mathrm{CH}_{2}\right)_{4}-\mathrm{OPhCH}=\mathrm{CBr}_{2}\right)$ : To a reaction mixture containing $\left(\mathrm{SOOCPh}-\equiv-\left(\mathrm{CH}_{2}\right)_{4}-\mathrm{OPhCH}=\right.$ $\left.\mathrm{CBr}_{2}\right)(1.01 \mathrm{~g}, 1.12 \mathrm{mmol}), \mathrm{TPP}(0.079 \mathrm{~g})$, CuI $(0.0115 \mathrm{~g})$, $\mathrm{Pd}(\mathrm{TPP})_{2} \mathrm{Cl}_{2}(0.0150 \mathrm{~g})$ triethylamine $(15 \mathrm{ml})$ and dioxane $(10 \mathrm{ml})$, monomer $6(2.0 \mathrm{~g}, 5.59 \mathrm{mmol})$, dissolved in dioxane $(30 \mathrm{ml})$ was added during $2 \mathrm{~h}$ at $80^{\circ} \mathrm{C}$ under nitrogen. The reaction was stirred under reflux overnight. The solid was filtered off, washed with methanol and dried in vacuum. To cleave the polymer bound material, 
the product was stirred with $1.5 \mathrm{~g} \mathrm{~K}_{2} \mathrm{CO}_{3}$ in $150 \mathrm{ml}$ methanol for $24 \mathrm{~h}$, solid was filtered off and extracted with chloroform.

\section{Measurements}

Molecular weights of the polymers were determined by GPC using a Varian 9012 instrument at $30^{\circ} \mathrm{C}$ in $\mathrm{CH}_{2} \mathrm{Cl}_{2}$ with polystyrene standard, universal column and flow of $1 \mathrm{ml} \mathrm{min}{ }^{-1}$ and by end group analysis using ${ }^{1} \mathrm{H}$ NMR. In the case of solution prepared polymers a signal of terminal acetylene $(1.80 \mathrm{ppm})$ and that $\mathrm{OCH}_{2}$ protons as a reference were used to determine number average molecular weight, while for polymers prepared using solid support a signal of methoxy terminal protons $(3.90 \mathrm{ppm})$ was taken. ${ }^{1} \mathrm{H}$ and ${ }^{13} \mathrm{C}$ NMR spectra were taken using a Varian spectrometer at $300 \mathrm{MHz}$ and $75.5 \mathrm{MHz}$, respectively, in DMSO- $d_{6}$, or $\mathrm{CDCl}_{3}$ with tetramethylsilane (TMS) as the internal standard. Absorption, emission and excitation spectra were measured with an automated Spex-FluoroMax spectrofluorimeter in $\mathrm{CHCl}_{3}$ solution. ${ }^{1} \mathrm{H}$ and ${ }^{13} \mathrm{C}$ isotropic shielding tensors of $\mathbf{A}, \mathbf{B}$, $\mathbf{C}$, and $\mathbf{D}$ model compounds were computed by the Gauge-Independent Atomic Orbital (GIAO) method ${ }^{4}$ for NMR spectra simulation at $3-21 G(d)$ level of theory. Excitation energies of $\mathbf{A}, \mathbf{B}, \mathbf{C}$, and $\mathbf{D}$ model compounds were calculated using geometries optimized at $\mathrm{HF} / 3$ $21 \mathrm{G}(\mathrm{d})$ followed by a single point energy calculations at B3LYP/6-31G(d) with Gaussian 94. ${ }^{5}$ The energies of long wave absorption maxima were taken as energy difference between lowest unoccupied (LUMO) and highest occupied (HOMO) orbitals. LUMO-HOMO energy difference obtained with the Becke three parameter hybrid (B3) exchange functional in combination with Lee-Yang-Parr (LYP) correlation functional yield excitation energies in good agreement with experimental values. ${ }^{6}$

\section{RESULTS AND DISCUSSION}

Monomer 6 was synthesized starting from 4-hydroxybenzaldehyde (1) and 5-hexyne-1-ol (3) in 3 steps (Scheme 1). Tosylation of $\mathbf{3}$ with $\mathrm{TsCl}$ produced tosylate 4. The alkylation of $\mathbf{1}$ with tosylate $\mathbf{4}$ gave compound $\mathbf{5}$ which was converted to monomer $\mathrm{AB}_{2}$ type (6) by the Wittig reaction with dibromotriphenylphosphinephosphorane.

The synthesis of solid supports is shown in Scheme 1. Aromatic polyamide $\mathrm{SOH}$ bearing phenolic hydroxyl on each repeat unit was synthesized by low temperature solution polycondensation in NMP starting from diamine $\mathbf{2}$ and terephthaloyl chloride. Soluble polymer was obtained with well defined structure when the exact stochiometric ratio of monomers is used. Diamine $\mathbf{2}$ was prepared in one step from aniline and benzaldehyde. Hydroxy-containing polyamide $\mathrm{SOH}$ was used to prepare two solid supports. The first one $(\mathrm{S}-\mathrm{OOCPhBr})$ was prepared by treating SOH with 4-bromobenzoyl chloride. The reaction produced polymer with about $80 \%$ substitution according to elemental analysis and the polymer lost solubility in common organic solvents attributed to unfavorable change in hydrophobic/hydrophilic balance after functionalization. The second support (SOOCPh$\left.\equiv-\left(\mathrm{CH}_{2}\right)_{4}-\mathrm{OPhCH}=\mathrm{CBr}_{2}\right)$ was prepared from S-

Polym. J., Vol. 31, No. 5, 1999

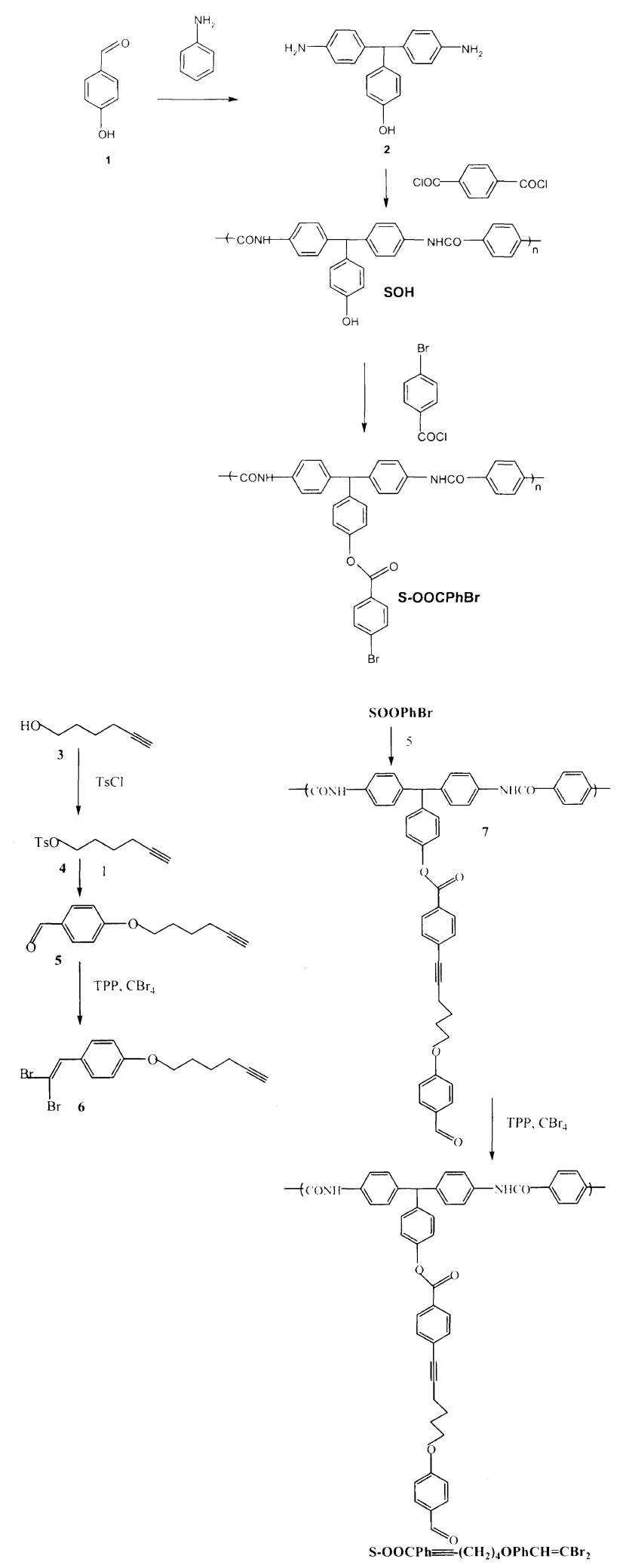

Scheme 1. Solid support and monomer synthesis.

OOCPhBr in two steps. The first was Pd-catalyzed crosscoupling of compound 5 with $\mathrm{S}-\mathrm{OOCPhBr}$ to give polymer 7 which was converted to $\mathrm{SOOCPh}-\equiv-\left(\mathrm{CH}_{2}\right)_{4}^{-}$ $\mathrm{OPhCH}=\mathrm{CBr}_{2}$ by the Wittig reaction with dibromotriphenylphosphinephosphorane. Both polymeric supports have $\mathrm{Br}$ atoms active in $\mathrm{Pd}$-catalyzed cross-coupling with terminal acetylenes. However, vinylic bromine of $\mathrm{SOOCPh}-\equiv-\left(\mathrm{CH}_{2}\right)_{4}-\mathrm{OPhCH}=\mathrm{CBr}_{2}$ is more reactive in cross-coupling reaction than aromatic bromine of $\mathrm{S}$ - 
OOCPhBr which makes differences between them. In the case of solid supported polymerization of monomer $\mathbf{6}$, it is the cross-coupling reaction that tethers growing hyperbranched molecules to the polymeric support. Support-bound hyperbranched polymer is cleaved by a simple $\mathrm{K}_{2} \mathrm{CO}_{3}$ catalyzed transesterification in $\mathrm{MeOH}$ as shown in Scheme 2.

The polymerization of monomer $\mathbf{6}$ without support produced polymer (Poly-6) completely soluble in chloroform. Figure 1 shows ${ }^{1} \mathrm{H}$ NMR and ${ }^{13} \mathrm{C}$ NMR spectra of Poly-6. To assign these spectra ${ }^{1} \mathrm{H}$ and ${ }^{13} \mathrm{C}$ shielding tensors of model compounds were computed with the GIAO method at HF/3-21G(d). The geometry of the model compounds was also optimized at $\mathrm{HF} / 3-21 \mathrm{G}(\mathrm{d})$. The results of calculation are presented in Table I. Compounds $\mathbf{A}$ and $\mathbf{B}$ represent models for terminal groups and perfectly branched repeat units of Poly-6 while

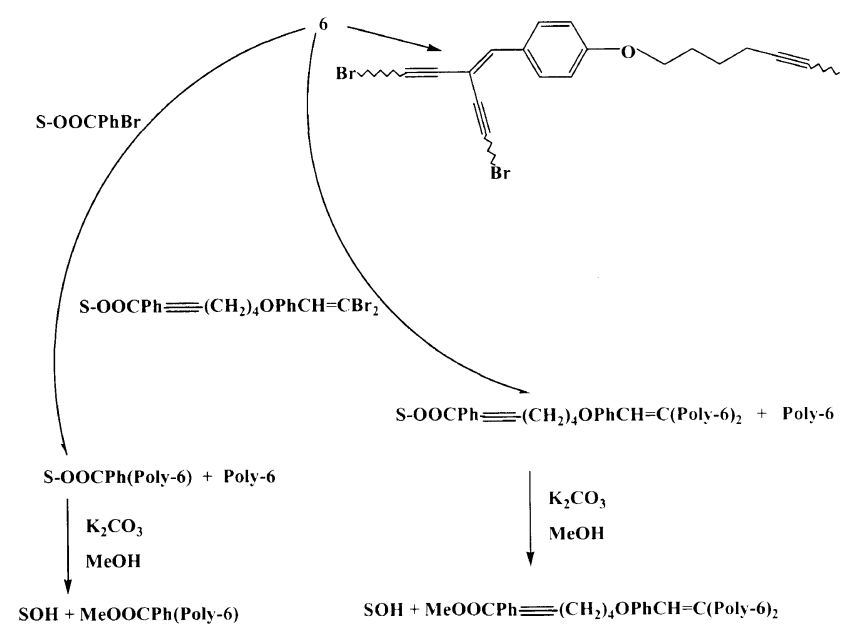

Scheme 2. structures $\mathbf{C}$ and $\mathbf{D}$ are models of two possible defects resulting from incomplete branching. As seen from Table I, there is a reasonably good agreement between computed and measured chemical shift for structure A (experimental chemical shifts were taken from NMR of monomer 6) making reliable other computed chemical shifts. Careful analysis of ${ }^{1} \mathrm{H}$ NMR spectrum of Poly-6 leads us to the conclusion that branching in the polymer is not perfect. Taking into account calculated chemical shifts, a doublet at $7.50 \mathrm{ppm}(J=9.0 \mathrm{~Hz})$ should be assigned to aromatic protons ortho to terminal $\mathrm{CH}=$ $\mathrm{CBr}_{2}$ groups $\left(\mathrm{H}^{3}\right.$ of structure $\left.\mathrm{A}\right)$ while a doublet at 7.62 ppm $(J=9.0 \mathrm{~Hz})$ is due to $\mathrm{H}^{3}$ of linear defect of type $\mathbf{D}$ $\left(\delta_{\text {calc }}=7.70 \mathrm{ppm}\right)$. A low field doublet at $7.72 \mathrm{ppm}$ should be a superposition of $\mathrm{H}^{3}$ of two structures. Perfectly branched $\mathbf{B}$ and linear defect $\mathbf{C}\left(\delta_{\text {calc }}=7.98 \mathrm{ppm}\right) .{ }^{13} \mathbf{C}$ NMR spectra of Poly-6 also confirm the existence of linear defects in the polymer. A signal at $136.3 \mathrm{ppm}$ is due to $\mathrm{C}^{\alpha}$ of terminal dibromovinyl groups (structure $\mathbf{A}$ ) while three closely located signals at $134.9,134.1$, and 133.2 should belong to $\mathbf{C}^{\alpha}$ of structures $\mathbf{B}, \mathbf{C}$, and $\mathbf{D}$. This agrees reasonably well with calculated $\mathbf{C}^{\alpha}$ chemical shifts (Table I). Assuming similar reactivity for two bromine atoms in dibromovinyl group (the number of linear defects of $\mathbf{C}$ and $\mathbf{D}$ type is the same) the degree of branching (DB) of Poly-6 can be estimated as follows:

$$
\mathrm{DB}=\left(I_{1}-I_{2}\right) /\left(I_{1}+I_{2}\right)
$$

Where $I_{1}$ and $I_{2}$ are integrals of doublets at 7.72 and $7.62 \mathrm{ppm}$, respectively (terminal $=\mathrm{CBr}_{2}$ not considered as branching). According to this calculated DB of Poly-6 is $30-35 \%$. A multiplet at $7.00-6.50 \mathrm{ppm}$ is composed of $\mathrm{H}^{2}$ signals of all four possible structures and $\mathrm{H}^{\alpha}$ signals of structures $\mathbf{B}$ and $\mathbf{C}$ and integrated for 2.5 protons. This agrees well with that calculated for DB of $30-35 \%$

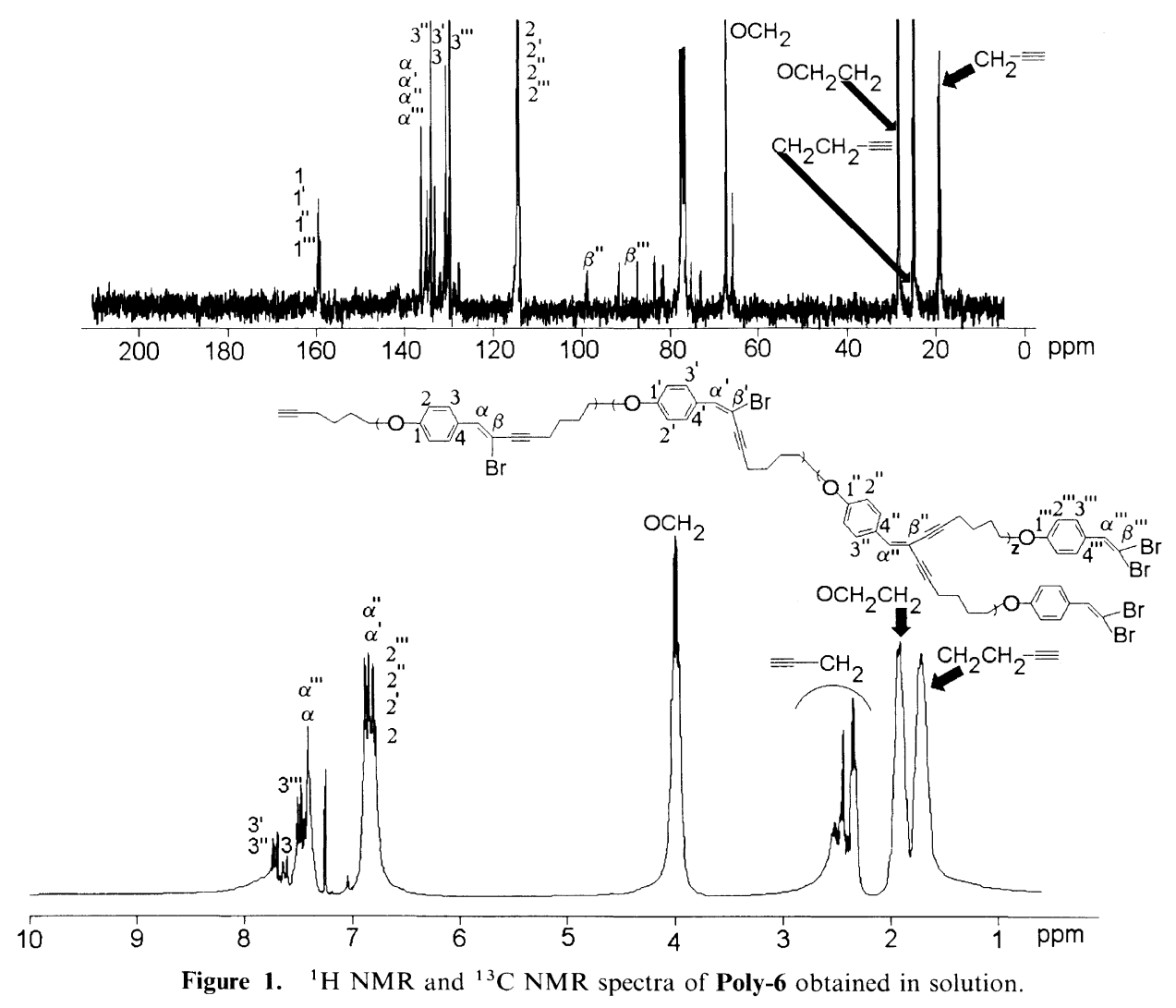


Table I. Computed chemical shifts $(\delta)$ of model compounds<smiles>COc1ccc(C=C(Br)Br)cc1</smiles>

A

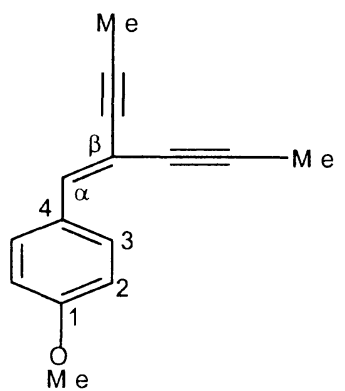

B

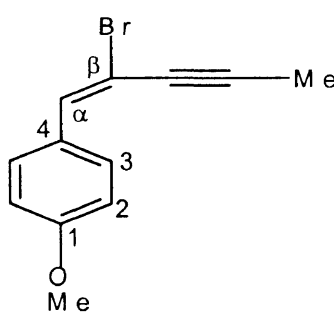

C

\begin{tabular}{lrrrrr} 
& \multicolumn{5}{c}{ Computed chemical shifts/ppm } \\
\cline { 2 - 6 } Atom & $\mathbf{A}$ & $\mathbf{A}_{\exp }$ & $\mathbf{B}$ & $\mathbf{C}$ & $\mathbf{D}$ \\
\hline $\mathrm{H}^{2}$ & 6.65 & 6.85 & 6.58 & 6.59 & 6.59 \\
$\mathrm{H}^{3}$ & 7.55 & 7.51 & 7.98 & 7.98 & 7.70 \\
$\mathrm{H}^{\alpha}$ & 7.21 & 7.39 & 6.78 & 6.68 & 7.22 \\
$\mathrm{C}^{\alpha}$ & 133.0 & 136.3 & 134.1 & 131.9 & 131.4 \\
\hline
\end{tabular}

$(2.6-2.7)$.

The number average molecular weight of Poly-6 determined from ${ }^{1} \mathrm{H}$ NMR using the signal of terminal acetylenic proton was 26000 while that measured by GPC gave 17500 with polydispersity of 3.5 . Both values are lower than that of poly $(\beta, \beta \text {-dibromo-4-ethynyl styrene })^{2}$ obtained by Pd-catalyzed cross-coupling polymerization of $\beta, \beta$-dibromo-4-ethynyl styrene $\left(M_{n}=36000\right)$. This is due to the fact that aromatic acetylene of $\beta, \beta$-dibromo4-ethynyl styrene is more active in the cross-coupling reaction than aliphatic acetylene of monomer $\mathbf{6}$. Low reactivity of aliphatic acetylene in monomer $\mathbf{6}$ could account for the relatively low DB of Poly-6 and probably is responsible for relative low DB of Poly-6.

The polymerization of monomer $\mathbf{6}$ in the presence of support $\mathrm{SOOCPhBr}$ followed by cleavage of attached Poly-6 gave no polymer at all. The only compound isolated after the cleavage was 4-bromomethylbenzoate formed due to the methanolysis of ester bond of $\mathrm{SOOCPhBr}$ as followed from NMR spectra. All monomer 6 was polymerized outside the support. This may be explained by difference in reactivity between aromatic and vinylic in the cross-coupling reaction. Increased reactivity of dibromovinyl bromine of monomer 6 led solely to homopolymerization. To solve this problem $\mathrm{SOOCPhBr}$ was converted to $\mathrm{SOOCPh}-\equiv$ $-\left(\mathrm{CH}_{2}\right)_{4}-\mathrm{OPhCH}=\mathrm{CBr}_{2}$. (Scheme 1) Similar to monomer 6, support SOOCPh- $\equiv-\left(\mathrm{CH}_{2}\right)_{4}-\mathrm{OPhCH}=\mathrm{CBr}_{2}$ bears a dibromovinyl function. On polymerization of monomer 6 in the presence of SOOCPh- $\equiv-\left(\mathrm{CH}_{2}\right)_{4}^{-}$ $\mathrm{OPhCH}=\mathrm{CBr}_{2}$ (monomer/support ratio $\left.=5 / 1\right)$ followed by cleavage of attached Poly-6 gave detached polymer with $10 \%$ yield. Figure 2 shows ${ }^{1} \mathrm{H}$ NMR and ${ }^{13} \mathrm{C}$ NMR

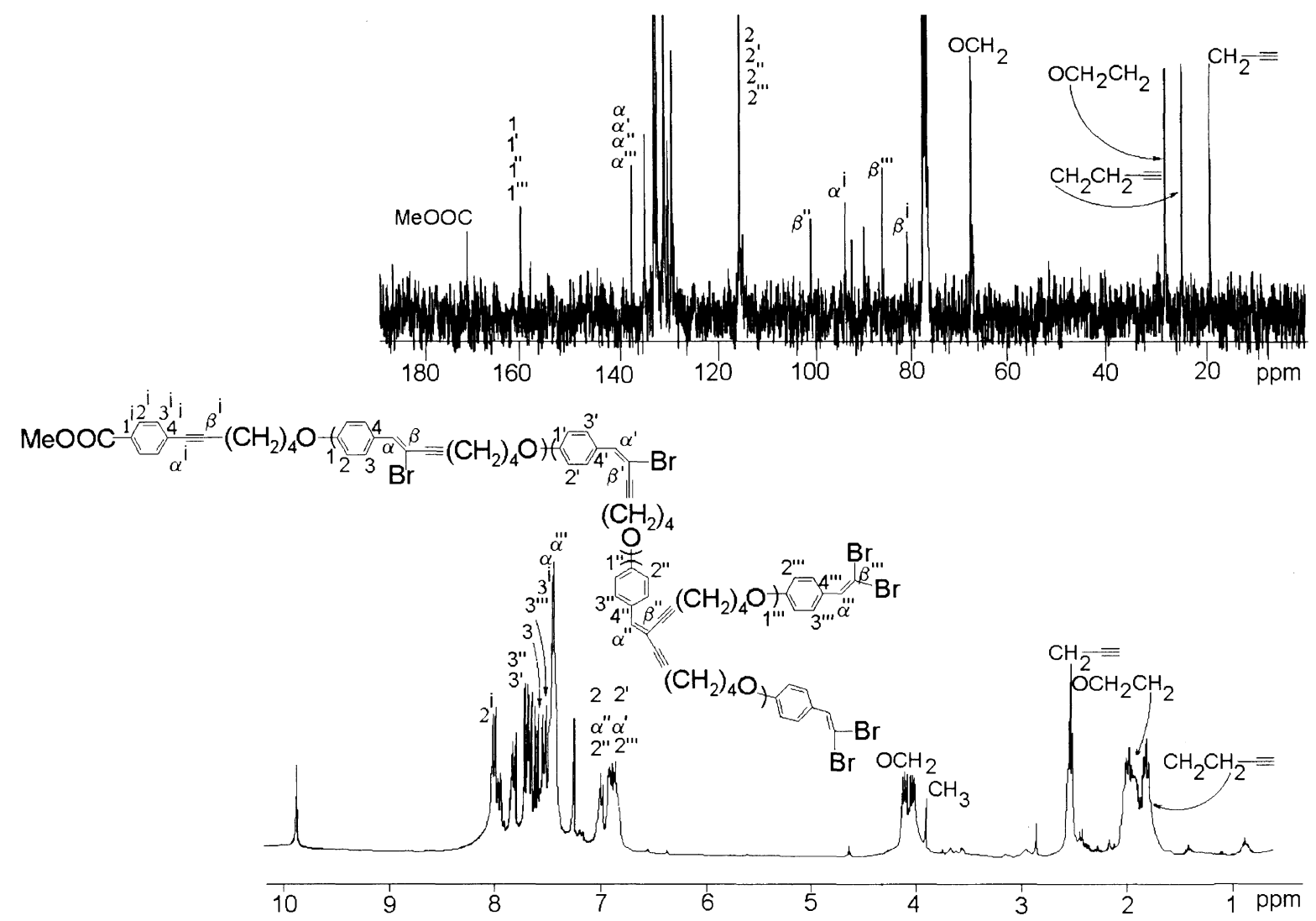

Figure 2. ${ }^{1} \mathrm{H}$ NMR and ${ }^{13} \mathrm{C}$ NMR spectra of Poly-6 obtained using solid support $\mathrm{SOOCPh} \equiv-\left(\mathrm{CH}_{2}\right)_{4} \mathrm{OPhCH}_{-} \mathrm{CBr}{ }_{2}$. 


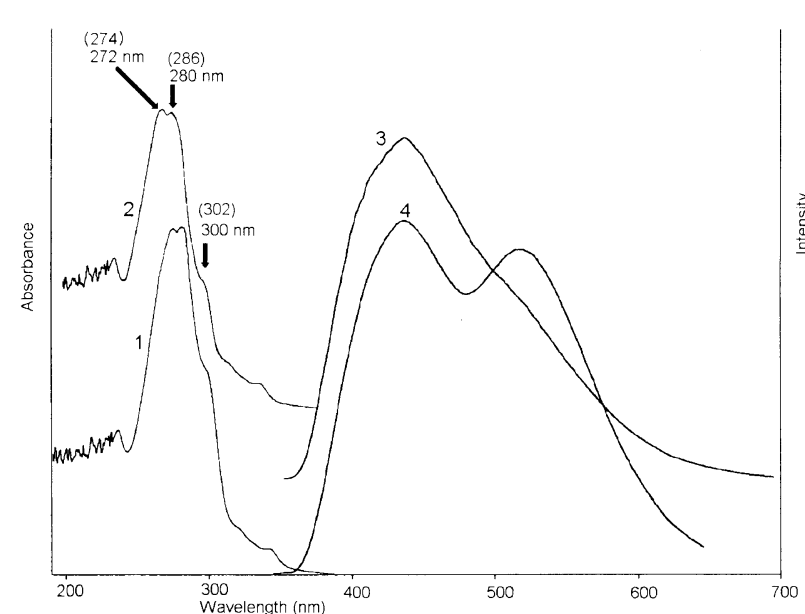

Figure 3. Absorption spectra of $\mathrm{CHCl}_{3}$ solutions of Poly-6 prepared without (1) and with (2) support SOOCPh- $\equiv-\left(\mathrm{CH}_{2}\right)_{4} \mathrm{OPhCH}=\mathrm{CBr}_{2}$. Emission spectra of $\mathrm{CHCl}_{3}$ solutions of Poly-6 prepared without (3) and with (4) support $\mathrm{SOOCPh}-\equiv-\left(\mathrm{CH}_{2}\right)_{4}-\mathrm{OPhCH}=\mathrm{CBr}_{2}$ (Excitation at $358 \mathrm{~nm}$ ).

spectra of detached Poly-6. Similar to Poly-6 prepared in solution Poly-6 synthesized using solid support is not perfectly branched. This follows from proton NMR spectra where the doublet at $7.60 \mathrm{ppm}$ is present along with other signals corresponding to monosubstituted structure D. However, DB of detached Poly-6 was of $60-65 \%$ when calculated by formula 1 which is twice that for Poly-6 synthesized in solution. $M_{n}$ of detached Poly-6 obtained by GPC and from ${ }^{1} \mathrm{H}$ NMR spectra was 7300 with polydispersity of 1.8 and 12000 , respectively. The fact agrees with Moore et al. work ${ }^{3}$ who were the first to observe self-limiting growth in solid supported hyperbranched polymerization. The origin of the phenomenon is steric hindrance due to polymeric support increase with molecular weight of the attached polymer. The increase of DB in solid-supported Poly-6 is attributed from our point of view to the cage-effect. Monomer 6 molecules trapped in the vicinity of growing polymer chain by the polymeric support have more time to react with second bromine atoms of dibromovinyl groups, thus increasing DB of Poly-6. The molecular weight measured by GPC is consistently lower than that calculated from ${ }^{1} \mathrm{H}$ NMR spectra due to more compact conformation of hyperbranched molecules compared to linear polystyrene.

Figure 3 shows absorption and emission spectra of Poly-6 synthesized with and without the solid support. All absorption spectra show shoulders at $300 \mathrm{~nm}$ and 3 maxims between 235 and $286 \mathrm{~nm}$. Long wave absorption maxims of the structures $\mathbf{A}, \mathbf{B}, \mathbf{C}$, and $\mathbf{D}$ were calculated theoretically using geometries optimized at $\mathrm{HF} / 3-21 \mathrm{G}(\mathrm{d})$ level of theory followed by a single point energy calculations at B3LYP/6-31G(d) and shown in the Figure 3 in brackets. As seen from the Figure 3 there is good agreement between observed and calculated positions of peaks which allows us to assign a shoulder at $300 \mathrm{~nm}$ to the contribution from structure $\mathbf{B}\left(\lambda_{\max (\text { calc })}=300 \mathrm{~nm}\right)$ while two close peaks at $270-272\left(\lambda_{\max (\text { calc })}=274 \mathrm{~nm}\right)$ and $278-280 \mathrm{~nm}\left(\lambda_{\max (\text { calc) }}=282 \mathrm{~nm}\right)$ could be due to monosubstituted structures $\mathbf{B}$ and $\mathbf{C}$, respectively. The peak from dibromostyryl terminal groups (structure $\mathbf{A}$ ) $\left(\lambda_{\max (\text { calc })}=248 \mathrm{~nm}\right)$ which should appear at around $250 \mathrm{~nm}$ cannot be distinguished clearly due to high absorption of solvent $\left(\mathrm{CHCl}_{3}\right)$ in this region. The absorption spectra of Poly-6 obtained with and without the solid support are similar and agree reasonably with NMR data. The emission spectra of Poly-6 obtained in solution with and without solid support are alike. Both are blue emitters emitting the light at 437-442 and $527 \mathrm{~nm}$ when excited at $358 \mathrm{~nm}$ The second maxim is concentration depended and can be attributed to eximer formation.

\section{CONCLUSIONS}

Novel hyperbranched polymer poly(4-(5-Hexynyloxy)$\beta, \beta$-dibromostyrene) was synthesized by $\mathrm{Pd}$-catalyzed cross-coupling reaction of 4-(5-hexynyloxy)- $\beta, \beta$-dibromostyrene in solution and using aromatic polyamide solid support. According to NMR data, the degree of branching of the polymer obtained in solution without solid support was of $30-35 \%$, while when using solid support the degree of branching increased to $60-65 \%$. $M_{n}$ of detached Poly-6 calculated from ${ }^{1} \mathrm{H}$ NMR spectra was lower than that of the polymer obtained in solution. It seems that monomer molecules trapped in the vicinity of growing polymer chain by the polymeric support have more time to react with second bromine atoms of dibromovinyl groups, thus increasing of the polymer. Drop in molecular weight when using solid support results from steric hindrances due to polymeric support increase with molecular weight of the attached polymer, thus limiting the molecular weight of the attached polymer.

Acknowledgments. This work was supported by a Grant from CONACyT with contract 25092E. Thanks are also due to M. A. Canseco for the assistance in UV spectroscopy.

\section{REFERENCES}

1. L. Fomina and R. Salcedo, Polymer, 37, 1723 (1996).

2. L. Fomina, S. Fomine, R. Salcedo, and T. Ogawa, Polym. J., 28, 1076 (1996)

3. P. Bharathi and J. Moore J. Am. Chem. Soc., 119, 3391 (1997).

4. K. Wolinski, J. Hilton, and P. Pulay J.Am. Chem. Soc., 112, 8251 (1990).

5. M. J. Frisch, G. W. Trucks, H. B. Schlegel, P. M. W. Gill, B. G. Johnson, M. A. Robb, J. R. Cheeseman, T. Keith, G. A. Petersson, J. A. Montgomery, K. Raghavachari, M. A. Al-Laham, V. G. Zakrzewski, J. V. Ortiz, J. B. Foresman, J. Cioslowski, B. B. Stefanov, A. Nanayakkara, M. Challacombe, C. Y. Peng, P. Y. Ayala, W. Chen, M. W. Wong, J. L. Andres, E. S. Replogle, R. Gomperts, R. L. Martin, D. J. Fox, J. S. Binkley, D. J. Defrees, J. Baker, J. P. Stewart, M. Head-Gordon, C. Gonzalez, and J. A. Pople, Gaussian, Inc., Pittsburgh, PA, 1995.

6. U. Salnzner, J. Lagowski, P. Pickup, and R. Poirier, J. Comp. Chem., 18, 1943 (1997). 